\title{
Consultations in Molecular Diagnostics
}

\section{Hereditary Apolipoprotein Al-Associated Amyloidosis in Surgical Pathology Specimens}

\author{
Identification of Three Novel Mutations in the APOA1 Gene
}

\author{
Magdalena Eriksson, ${ }^{\star}$ Stefan Schönland, ${ }^{\dagger}$ \\ Saniye Yumlu, ${ }^{*}$ Ute Hegenbart, ${ }^{\dagger}$ Hanna von Hutten, ${ }^{*}$ \\ Zarina Gioeva, ${ }^{*}$ Peter Lohse, ${ }^{\ddagger}$ Janine Büttner, ${ }^{\S}$ \\ Hartmut Schmidt, ${ }^{\text {" }}$ and Christoph Röcken* \\ From the Department of Pathology,* and the Medical Clinic of \\ Gastroenterology, Hepatology, and Endocrinology, Charité \\ University Hospital, Berlin; Medical Department $V^{\dagger}$ Amyloidosis \\ Clinic, Hematology, University of Heidelberg, Heidelberg; the \\ Department of Clinical Chemistry - Grosshadern, ${ }^{\ddagger}$ University of \\ Munich, Munich; and Transplant Hepatology, "University of \\ Münster, Münster, Germany
}

Apolipoprotein AI-derived (AApoAI) amyloidosis may present either as a non-hereditary form with wildtype protein deposits in atherosclerotic plaques or as a hereditary form due to germline mutations in the $A P O A 1$ gene. Currently, more than 50 apoAI variants are known, and 13 are associated with amyloidosis. We describe six patients with AApoAI amyloidosis due to $A P O A 1$ germline mutations that affect the larynx, small intestine, large intestine, heart, liver, kidney, uterus, ovary, or pelvic lymph nodes. In each patient, the amyloid showed a characteristic apple green birefringence when viewed under polarized light after Congo red staining and was immunoreactive with antibodies against apoAI. Sequence analyses revealed one known (p.Leu75Pro) and three novel APOA1 mutations that included gene variations leading to two different frameshifts (p.Asn $74 \mathrm{fs}$ and p.Ala154fs) and one amino acid exchange (p.Leu170Pro). These three novel mutations extend our knowledge about both the location of the mutations and the organ distribution in hereditary AApoAI amyloidosis. Thirteen of the now sixteen amyloidogenic mutations are localized in two hot-spot regions that span residues 50 to 93 and 170 to 178 . The organ distribution and clinical presentation of AApoAI amyloidosis seems to depend on the position of the mutation. Patients with alterations in codons 1 to 75 mostly develop hepatic and renal amyloidosis, while carriers of mutations in residues 173 to 178 mainly suffer from cardiac, laryngeal, and cutaneous amyloidosis. (J Mol Diagn 2009, 11:257-262; DOI: 10.2353/jmoldx.2009.080161)

The amyloidoses are a large group of heterogeneous diseases characterized by insoluble protein and peptide aggregates oriented in a $\beta$-pleated sheet structure, forming amyloid fibrils of 10 to $12 \mathrm{~nm}$ diameter. More than 26 different proteins have been identified to form amyloid. Depending on the histoanatomical distribution and amount, amyloid may cause progressive and life-threatening organ dysfunction. ${ }^{1}$ Amyloid may be acquired or hereditary in origin, and it can deposit locally or present as a systemic disease. Due to the diversity of the precursor proteins with no sequence homology between them, it has been impossible to find any common primary structural or functional motif that predicts the amyloidogenicity of a peptide or protein. In this respect, hereditary amyloidoses are particularly interesting. They are caused by germline mutations, which increase the propensity of the affected protein to form aggregates under particular circumstances. Variants of transthyretin, apolipoprotein $\mathrm{Al}$ (apoAI), apolipoprotein All, fibrinogen A $\alpha$-chain, gelsolin, and lysozyme are some of the proteins known to cause hereditary amyloidosis. The most frequent form of hereditary amyloidosis is the transthyretin-derived ATTR amyloidosis, which clinically presents with polyneuropathy and/or cardiomyopathy. ${ }^{2}$

Apolipoprotein Al-derived (AApoAI) amyloidosis can be present as a non-hereditary form with wild-type protein deposits in atherosclerotic plaques, ${ }^{3}$ or as a hereditary form with the variant protein depositing more sys-

Supported by grants of the European Union (EU FP6 EURAMY).

M.E. and S.S. contributed equally to the manuscript.

Accepted for publication April 28, 2008.

Address reprint requests to Prof. Dr. med. Christoph Röcken, Department of Pathology, Charité University Hospital, Charitéplatz 1, D-10117 Berlin, Germany. E-mail: christoph.roecken@charite.de. 
Table 1. ApoA1 Mutations Associated with AApoAI Amyloidosis

\begin{tabular}{lll}
\hline \multicolumn{1}{c}{ Variant (mature protein) } & \multicolumn{1}{c}{ Clinical manifestations/found amyloid sites } & Reference \\
\hline p.Gly26Arg & Renal failure, gastrointestinal amyloid, peripheral neuropathy & 7,8 \\
p.Trp50Arg & Renal failure & 9 \\
p.Leu60Arg & Renal failure & 10 \\
p.Leu64Pro & Renal failure & 11 \\
p.Leu60_Phe71delinsValThr & Liver failure & 12 \\
p.Glu70_Trp72del & Renal failure & 13 \\
p.Asn74fs & Gastrointestinal amyloid, renal failure, amyloid detected in uterus, & Current report \\
p.Leu75Pro & ovaries, pelvic lymph nodes & 14,15 Current report \\
p.Leu90Pro & Renal failure, hepatic amyloid, gastrointestinal amyloid & 16 \\
p.Lys107del & Cardiomyopathy, cutaneous amyloid & 17 \\
p.Ala154fs & Aortic intimal amyloid & Current report \\
p.Leu170Pro & Renal amyloid & Current report \\
p.Arg173Pro & Amyloid in larynx & 18 \\
p.Leu174Ser & Cardiomyopathy, cutaneous and laryngeal amyloid & 19 \\
p.Ala175Pro & Cardiomyopathy & 20 \\
p.Leu178His & Laryngeal amyloid & 21 \\
\hline
\end{tabular}

temically. The clinical manifestations of hereditary AApoAl amyloidosis frequently involve liver, kidney, larynx, skin, and myocardium. In rarer cases, amyloid is also found in the testes and adrenal glands. ${ }^{4} \mathrm{ApoAl}$ is a plasma protein of $28 \mathrm{kDa}$ synthesized by the liver and the small intestine. It is the main protein of high-density lipoprotein particles and important for the formation and metabolism of high-density lipoprotein cholesterol esters. ${ }^{5}$ Mature apoAl consist of 243 amino acids encoded by exons 3 and 4 of the APOA1 gene. ${ }^{6}$ More than 50 apoAl variants have been described, ${ }^{4}$ and about half of them are associated with a decreased plasma level of high-density lipoprotein-apoAl. These apoAl variants either affect lecithin:cholesterol acyltransferase activity or promote the formation of amyloid. ${ }^{5}$ To date, 13 mutations are known to be associated with hereditary AApoAl amyloidosis (Table 1). ${ }^{7-21}$ The majority of the germline mutations are nucleotide substitutions, but two variants are caused by deletions ${ }^{13,17}$ and another one is due to a deletion/insertion mutation. ${ }^{12}$

In this report, we describe six German patients with hereditary AApoAl amyloidosis, presenting with one known and three novel mutations in the APOA1 coding sequence.

\section{Case Reports}

Six German patients (four women and two men) with hereditary AApoAl amyloidosis were studied. Patients were retrieved from the Amyloid Registries of the University Hospitals in Berlin and Heidelberg between June 2001 and August 2008. Following the identification of cases with AApoAl amyloidosis, all patients gave written informed consent for genomic analyses. The study was performed in accordance with the guidelines set out by the German government and the local Ethics Committee of the University of Berlin.

\section{Patient No. 1}

A normotensive woman was admitted with nephrotic syndrome at the age of 58 years, and a kidney biopsy was taken. No further clinical information was available from this patient.
Patient No. 2

A hysteroadnexectomy was performed in a 48-year-old woman because of a serous borderline tumor of the right ovary. She was on hemodialysis twice a week since June 2000 due to terminal renal failure. She also suffered from secondary hyperparathyroidism, anemia, and hypertension. Tissue samples were obtained from the hysteroadnexectomy specimens.

\section{Patient No. 3}

A rectal biopsy of this 67-year-old woman was submitted for the immunohistochemical classification of amyloid. Patients No. 2 and No. 3 are related. No further clinical information was available.

\section{Patient No. 4}

A 54-year-old woman had a short history of discomfort in the upper abdomen after an episode of diarrhea and nausea nine months earlier. Biopsies retained from a duodenoscopy and colonoscopy revealed amyloid. She also had a history of type I diabetes for 20 years and of renal failure without nephrotic syndrome. No symptoms of dyspnea, polyneuropathy, or other organ involvement were present. Analysis of a kidney biopsy excluded diabetic nephropathy and revealed minimal renal amyloidosis. Vasculopathy was determined as the main cause of renal failure. In the course of the clinical work-up for liver transplantation, a cardiac biopsy was obtained, and cardiac amyloidosis was found. The daughter, sister, mother, and grandmother of the patient all suffer from type I diabetes, while the father died of leukemia.

\section{Patient No. 5}

A 52-year-old man was suffering from swallowing complaints for 6 years. A biopsy from the vocal cord revealed amyloid deposits in the larynx. The patient showed no symptoms of systemic amyloidosis. All laboratory values 

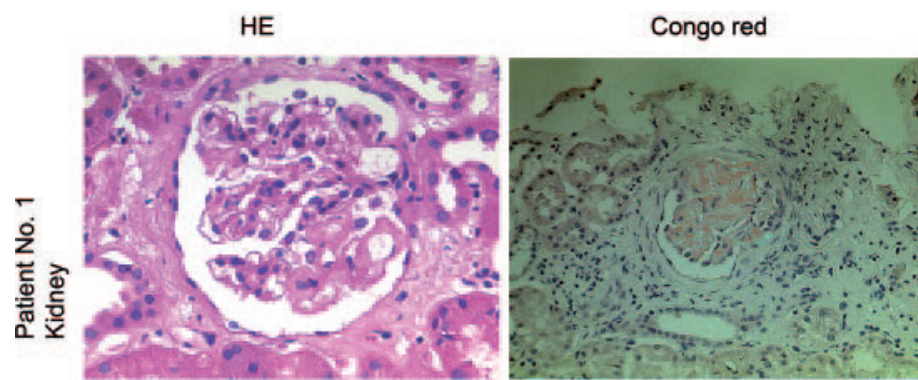

Anti-apoAl-antibody
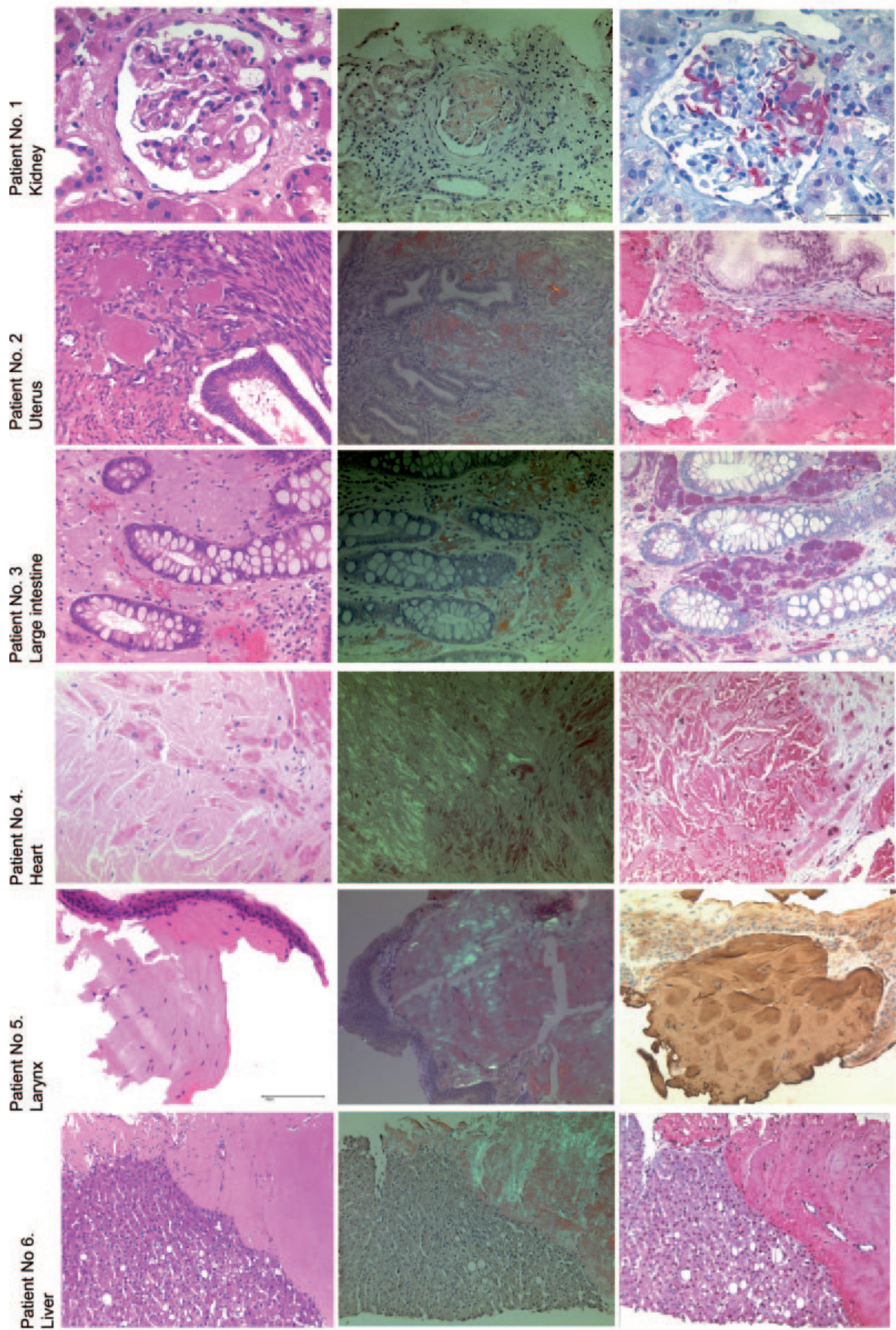

Figure 1. Biopsies from the six patients with AApoAI amyloidosis.Histological examination of the biopsy and resection specimens revealed homogeneous eosinophilic deposits in H\&E-stained sections (left panel). Same areas produced a typical apple green birefringence in polarized light after Congo red (CR) staining (center). Staining with an anti-apoAI antibody (right panel) showed a strong and even immunoreactivity of these amyloid deposits in every patient specimen. Sections from the patients $1-4$ and 6 were stained with the alkaline phosphatase system (red color), whereas the section from patient No. 5 was stained with a DAB substrate kit (brown color). Scale bar $=100 \mu \mathrm{m}$. 
were normal. Ultrasound of the abdomen as well as electrocardiogram and echocardiography were also normal. There was no family history of amyloidosis.

\section{Patient No. 6}

A 41-year-old man presented with elevated liver enzymes. The main symptom was itching. A liver biopsy revealed amyloidosis. The patient's grandmother had died of an undiagnosed liver disease at the age of 65 years.

\section{Materials and Methods}

\section{Histology and Immunohistochemistry}

The biopsies were fixed in formalin and embedded in paraffin. Serial sections were stained with H\&E. Amyloid was analyzed by viewing Congo red-stained sections under polarized light. Immunohistochemistry was performed with commercially available monoclonal antibodies directed against AA amyloid (1:600) and polyclonal antibodies against amyloid P component (1:5000), fibrinogen (1:2000), lysozyme (1:3000), transthyretin (1:4000), $\lambda$-light chain (1: $160,000)$, and $\kappa$-light chain $(1: 160,000)$ (all DAKO, Hamburg, Germany), as well as with non-commercially available polyclonal antibodies directed against apolipoprotein Al (1: 1000), ${ }^{22} \lambda$-light chain-derived amyloid proteins (AL1, $1: 3000$ ), ${ }^{23}$ and anti- $\lambda$-light chain peptide antibodies (AL3, ${ }^{24}$ $1: 250$ and AL7, 1:500, peptide used for antibody production as described by others ${ }^{25}$ ). Immunostaining was done with the BenchMark XT immunostainer using the ultraView Universal Alkaline Phosphatase Red Detection Kit (both Ventana Medical Systems, Inc., Tucson, Arizona) or the NOVADetect DAB-Substrate Kit (Dianova, Hamburg, Germany). Before the incubation with primary antibodies, sections were pretreated with Cell Conditioning 1 according to the manufacturer's instructions (CC1; Ventana) or with sodium citrate (four times, 5 minutes, $600 \mathrm{~W}$, microwave oven). The specificity of the immunostaining was verified using specimens containing known classes of amyloid (AA amyloid, transthyretin, $\lambda$-light chain), or by using positive controls recommended by the manufacturers (remaining antibodies). Omission of the primary antibodies served as a negative control.

\section{DNA Sequence Analysis}

Genomic DNA was isolated from peripheral blood leukocytes using the QIAamp DNA blood mini kit (Qiagen,
Hilden, Germany). In one case, total genomic DNA was extracted from formalin-fixed paraffin-embedded tissue with the QIAamp DNA mini kit (Qiagen) as described by the manufacturer. Amplification of APOA1 exons 1-4 was performed by PCR with the following specific primer pairs (Biotez, Berlin, Germany): exon 1-2 (489 bp) forward 5'-AAGTTCCACATTGCCAGGAC-3' and reverse 5'-AGAGGCAGCAGGTTTCTCAC-3'; exon 3 (376 bp) forward 5'AGAGGCAGCAGGTTTCTCAC-3' and reverse 5'-AATATCTGATGAGCTGGGCC-3'; exon 4a (493bp) forward 5'-AAGAGAAGCTGAGCCCACT-3' and reverse 5'-CCCTACAGCGACGAGCTG-3'; and exon 4b (400 bp) forward 5'-CTGGAAATGCTAGGCCAC-3' and reverse 5'-CAGCTTCTTTCTTTTGGGAGAA-3'. A 30- $\mu$ l reaction mixture contained $200 \mathrm{ng}$ DNA, $1 \mu \mathrm{mol} / \mathrm{L}$ of the exon-specific primers, 1x PCR buffer, $1.5 \cup$ Taq polymerase, $0.2 \mu \mathrm{mol} / \mathrm{L}$ dNTPs, and Q-solution in concentrations recommended by the manufacturer (Qiagen). The following thermocycling conditions were used: initial denaturation at $94^{\circ} \mathrm{C}$ for 3 minutes, 40 cycles of $94^{\circ} \mathrm{C}$ for 1 minute, $60^{\circ} \mathrm{C}\left(61^{\circ} \mathrm{C}\right.$ for the exon $4 \mathrm{a}$ primer pair) for 1.5 minutes, $72^{\circ} \mathrm{C}$ for 1 minute, and a final elongation step at $72^{\circ} \mathrm{C}$ for 7 minutes. A negative control with water instead of DNA was included in each PCR run, and blood isolated from an individual with wild-type APOA1 served as a positive control. The quality and size of the generated PCR products were analyzed by agarose gel electrophoresis. Fragments were purified with the ExOSAP-IT kit for PCR product clean-up (USB Corp., Cleveland, $\mathrm{OH})$. The PCR products were sequenced in both directions with the ABI PRISM BigDye Terminator v3.1 Ready Reaction Cycle Sequencing kit (Applied Biosystems, Foster City, CA) using the same set of primers as described above. Sequences were analyzed on an ABI PRISM 3130 Genetic Analyzer.

\section{Results}

\section{Histology and Immunohistochemistry}

In each patient, the amyloid deposits showed a characteristic apple green birefringence when viewed under polarized light after Congo red staining (Figure 1). Amyloid was present as glomerular (kidney), vascular, or interstitial deposits. In patient No. 1, focal glomerular amyloid deposits were found in a kidney biopsy. Patient No. 2 had massive vascular and interstitial deposits in the uterus, ovaries, soft tissue, and pelvic lymph nodes. $\mathrm{Pa}$ tients No. 3 and No. 4 were found to have massive

Table 2. AApoAI Patients, Mutations, and Tissue Sites

\begin{tabular}{|c|c|c|c|c|c|c|}
\hline $\begin{array}{l}\text { Patient } \\
\text { no. }\end{array}$ & Sex & Age (y) & Mutation (cDNA) & $\begin{array}{l}\text { Mutation } \\
\text { (protein) }\end{array}$ & Analyzed tissue sites & Histology \\
\hline 1 & Female & 58 & c.460_461dupGC & p.Ala154fsX47 & Kidney & $\begin{array}{l}\text { Glomerular amyloid deposits; no renal } \\
\text { vascular deposits }\end{array}$ \\
\hline 2 & Female & 48 & c.293_294insA & p.Asn74Lysfs & $\begin{array}{l}\text { Uterus, ovaries, pelvic } \\
\text { lymph nodes }\end{array}$ & $\begin{array}{l}\text { Massive vascular and interstitial } \\
\text { amyloid deposits }\end{array}$ \\
\hline 3 & Female & 67 & c.293_294insA & p.Asn74Lysfs & Large intestine & Interstitial amyloid deposits \\
\hline 4 & Female & 54 & c. $296 \overline{\mathrm{T}}>\mathrm{C}$ & p.Leu75Pro & Small intestine, Heart & Interstitial amyloid deposits \\
\hline 5 & Male & 52 & c. $581 \mathrm{~T}>\mathrm{C}$ & p.Leu170Pro & Larynx & Subepithelial and interstitial amyloidosis \\
\hline 6 & Male & 41 & c. $296 \mathrm{~T}>\mathrm{C}$ & p.Leu75Pro & Liver & Massive amyloid deposits in portal tracts \\
\hline
\end{tabular}



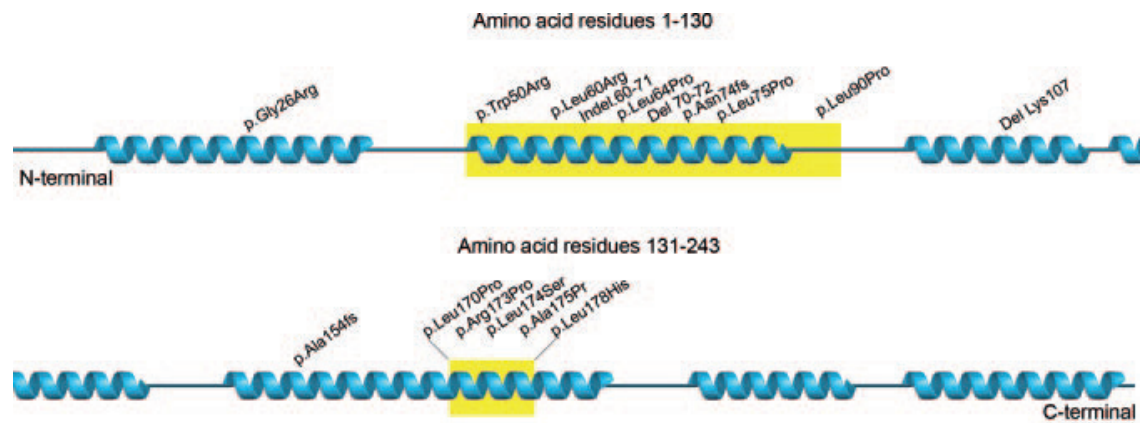

Figure 2. Distribution of ApoAI mutations with regard to the proteins secondary structure. The hot spot regions spanning residues 50 to 93 and 170 to 178 are marked in yellow and the twisted blue areas represent the $\alpha$-helices. The picture of the secondary structure of ApoAI was obtained from the database Jpred at the European Bioinformatics Institute and modified. vascular and interstitial amyloid deposits in the biopsies of the large and small intestine, respectively. Patient No. 4 also had interstitial amyloid deposits in an endomyocardial biopsy, while patient No. 5 had subepithelial deposits in a laryngeal biopsy. In patient No. 6, amyloid was found in a liver biopsy and was restricted to the portal tracts (Figure 1). Table 2 summarizes the biopsy sites where amyloid was found in our patients.

The amyloid deposits in every patient showed an intense and even staining with antibodies directed against amyloid $\mathrm{P}$ component and apoAl (Figure 1). No significant immunostaining was found with antibodies directed against AA amyloid, fibrinogen, lysozyme, $\beta 2$-microglobulin, $\lambda$ - and $\kappa$-light chain, or transthyretin.

\section{DNA Sequence Analysis}

Sequence analysis revealed a mutation in the coding sequence of the APOA1 gene in all six patients. Patient No. 1 had a GC duplication (c.460_461dupGC), leading to a frameshift (p.Ala154fsX48) resulting in a truncated protein of 200 amino acids instead of 243 amino acids. Two of the patients ( 2 and 3 ) carried an adenine insertion at nucleotide position 294 (c.293_294insA), which also leads to a frameshift (p.Asn74fsX106). Theoretically, this mutation would result in a mutant protein of 178 amino acids, where the first 73 residues are identical to the wild-type apoAl, and the remaining 105 amino acids are completely different. Patient No. 5 was heterozygous for a c.581T $>$ C transition, resulting in a p.Leu170Pro substitution. These three mutations have heretofore not been described. One known mutation (c.296T>C or p.Leu75Pro) was found in patients 4 and 6 .

\section{Discussion}

Hereditary amyloidosis was first described by Ostertag in 1932 and again in the early 1950's. ${ }^{26,27}$ Even if it is considered to be a rare disease, it has to be separated from other forms of systemic amyloidosis, such as the more common immunoglobulin-derived $\mathrm{AL}$ amyloidosis, as these diseases require a different patient management. Lachmann et al reported that about $10 \%$ of the patients diagnosed with $\mathrm{AL}$ amyloidosis were misdiagnosed and had to be reclassified as hereditary amyloidosis, eg, transthyretin-derived ATTR amyloidosis or fibrinogen $\mathrm{A} \alpha$-chain-derived AFib amyloidosis. ${ }^{20}$ In the patient series of the Amyloid Registry of the Charité University Hospital and of the University Hospital in Heidelberg, approximately $5 \%$ and $3 \%$ of the patients were found to suffer from hereditary amyloidosis, respectively (unpublished observation). Recent reports describe relatively large patient cohorts and families with hereditary amyloidosis ${ }^{22,28-30}$ emphasizing the importance of genetic analyses in the diagnostic work-up of amyloidosis.

We here present six patients with mutations in the coding sequence of the APOA1 gene leading to AApoAl amyloidosis. Three of the mutations have not been described hitherto and extend the number of APOA1 mutations associated with AApoAl amyloidosis to sixteen (Table 1). ${ }^{7-21}$ Half of these mutations affect residues 50 to 93. ${ }^{3,4}$ One of the novel frameshift mutations, p.Asn74fs is also located within this region. The bp exchange affecting residue 170, in contrast, is present in a region where four other amyloidogenic mutations have been reported. Three of the sixteen mutations, including one of the novel mutations described here, are affecting residues outside these two hot spot regions (Figure 2).

The N-terminal peptide fragments 1 to 100 of apoAl have been found in the amyloid deposits of other AApoAl patients, ${ }^{12,19,31-32}$ which illustrates the propensity of this region for fibrillogenesis. Amyloid deposits consisting mainly of $\mathrm{N}$-terminal fragments of the precursor protein are also common in other types of amyloid.23,33 The antibody used in this study is directed against an epitope within the first 40 amino acid residues of apoAl. ${ }^{22}$ Strong immunostaining of the amyloid deposits with our antiapoAl antibody therefore indicates that the $\mathrm{N}$-terminal region of apoAl is deposited in all our six patients.

The histoanatomical distribution and clinical manifestation of hereditary AApoAI amyloidosis seems to depend on the location of the APOA1 mutation. Patients with gene mutations affecting residues 1 to 75 mainly suffer from hepatic and renal amyloidosis, while mutations in codons 173 to 178 mainly cause AApoAI amyloidosis of the heart, larynx, and skin (Table 1). ${ }^{7-21}$ Correspondingly, the patient carrying p.Leu170Pro suffered from laryngeal amyloidosis. The frameshift mutation with the first affected amino acid at position 74 resulted in massive amounts of amyloid being deposited in the uterus and pelvic soft tissue in one patient and in the gastrointestinal tract in another. No other organ or biopsy site was available for analysis and the extent of amyloid infiltration in these patients cannot be determined. Nevertheless, it is likely 
that this highly altered apoAl variant can affect several organs and tissue sites.

Interestingly, four of the six patients described here were diagnosed within the last 1.5 years. This was achieved by a combination of extensive and thorough immunohistochemical staining, using a large panel of antibodies directed against eight amyloid precursor proteins followed by molecular biological studies on genomic DNA. Genetic analysis is crucial to detect hereditary amyloidosis in time, since some types can be treated by liver or kidney transplantation. It is also of central prognostic value for family members potentially carrying the same mutation. Correlating the different $A P O A 1$ mutations with clinical features may, in addition, also help to improve the early detection of mutation carriers.

In conclusion, the three novel mutations described here extend our knowledge about the underlying mutations and the affected organs in patients with hereditary AApoAl amyloidosis. Thirteen of the sixteen mutations described in the APOA1 gene are located in one of the two hot spot regions spanning residues 50 to 93 and 170 to 178 .

\section{References}

1. Westermark P: Aspects on human amyloid forms and their fibril polypeptides. FEBS J 2005, 272:5942-5949

2. Benson MD, Kincaid JC: The molecular biology and clinical features of amyloid neuropathy. Muscle Nerve 2007, 36:411-423

3. Mucchiano GI, Jonasson L, Häggqvist B, Einarsson E, Westermark P: Apolipoprotein A-I-derived amyloid in atherosclerosis. Its association with plasma levels of apolipoprotein $\mathrm{A}-\mathrm{I}$ and cholesterol Am J Clin Pathol 2001, 115:298-303

4. Obici L, Franceschini G, Calabresi L, Giorgetti S, Stoppini M, Merlini G, Bellotti V: Structure, function and amyloidogenic propensity of apolipoprotein A-I. Amyloid 2006, 13:191-205

5. Sorci-Thomas MG, Thomas MJ: The effects of altered apolipoprotein A-I structure on plasma HDL concentration. Trends Cardiovasc Med 2002, 12:121-128

6. Karathanasis SK, Zannis VI, Breslow JL: Isolation and characterization of the human apolipoprotein A-I gene. Proc Natl Acad Sci USA 1983, 80:6147-6151

7. van Allen MW, Frohlich JA, Davis JR: Inherited predisposition to generalized amyloidosis. Clinical and pathological study of a family with neuropathy, nephropathy, and peptic ulcer. Neurology 1969, 19:10-25

8. Nichols WC, Gregg RE, Brewer HB, Jr., Benson MD: A mutation in apolipoprotein A-I in the lowa type of familial amyloidotic polyneuropathy. Genomics 1990, 8:318-323

9. Booth DR, Tan SY, Booth SE, Hsuan JJ, Totty NF, Nguyen O, Hutton T, Vigushin DM, Tennent GA, Hutchinson WL: A new apolipoprotein Al variant, Trp50Arg, causes hereditary amyloidosis. QJM 1995;88: 695-702

10. Soutar AK, Hawkins PN, Vigushin DM, Tennent GA, Booth SE, Hutton T, Nguyen O, Totty NF, Feest TG, Hsuan JJ: Apolipoprotein Al mutation Arg-60 causes autosomal dominant amyloidosis. Proc Natl Acad Sci USA 1992;89:7389-7393

11. Murphy CL, Wang S, Weaver K, Gertz MA, Weiss DT, Solomon A: Renal apolipoprotein A-I amyloidosis associated with a novel mutant Leu64Pro. Am J Kidney Dis 2004, 44:1103-1109

12. Booth DR, Tan SY, Booth SE, Tennent GA, Hutchinson WL, Hsuan JJ, Totty NF, Truong O, Soutar AK, Hawkins PN, Bruguera M, Caballeria J, Sole M, Campistol JM, Pepys MB: Hereditary hepatic and systemic amyloidosis caused by a new deletion/insertion mutation in the apolipoprotein Al gene. J Clin Invest 1996, 97:2714-2721

13. Persey MR, Booth DR, Booth SE, van Zyl-Smit R, Adams BK, Fattaar AB, Tennent GA, Hawkins PN, Pepys MB: Hereditary nephropathic systemic amyloidosis caused by a novel variant apolipoprotein A-I. Kidney Int 1998, 53:276-281

14. Coriu D, Dispenzieri A, Stevens FJ, Murphy CL, Wang S, Weiss DT,
Solomon A: Hepatic amyloidosis resulting from deposition of the apolipoprotein A-I variant Leu75Pro. Amyloid 2003, 10:215-223

15. Obici L, Palladini G, Giorgetti S, Bellotti V, Gregorini G, Arbustini E, Verga L, Marciano S, Donadei S, Perfetti V, Calabresi L, Bergonzi C, Scolari F, Merlini G: Liver biopsy discloses a new apolipoprotein A-I hereditary amyloidosis in several unrelated Italian families. Gastroenterology 2004, 126:1416-1422

16. Hamidi AL, Liepnieks JJ, Hamidi AK, Uemichi T, Moulin G, Desjoyaux E, Loire R, Delpech M, Grateau G, Benson MD: Hereditary amyloid cardiomyopathy caused by a variant apolipoprotein A1. Am J Pathol 1999, 154:221-227

17. Amarzguioui M, Mucchiano G, Häggqvist B, Westermark P, Kavlie A, Sletten K, Prydz H: Extensive intimal apolipoprotein A1-derived amyloid deposits in a patient with an apolipoprotein A1 mutation. Biochem Biophys Res Commun 1998, 242:534-539

18. Hamidi AK, Liepnieks JJ, Nakamura M, Parker F, Benson MD: A novel apolipoprotein A-1 variant. Arg173Pro, associated with cardiac and cutaneous amyloidosis. Biochem Biophys Res Commun 1999, 257:584-588

19. Obici L, Bellotti V, Mangione P, Stoppini M, Arbustini E, Verga L, Zorzoli I, Anesi E, Zanotti G, Campana C, Vigano M, Merlini G: The new apolipoprotein A-I variant Leu(174) $\rightarrow$ Ser causes hereditary cardiac amyloidosis, and the amyloid fibrils are constituted by the 93-residue N-terminal polypeptide. Am J Pathol 1999, 155:695-702

20. Lachmann HJ, Booth DR, Booth SE, Bybee A, Gilbertson JA, Gillmore JD, Pepys MB, Hawkins PN: Misdiagnosis of hereditary amyloidosis as $\mathrm{AL}$ (primary) amyloidosis. N Engl J Med 2002, 346:1786-1791

21. de Sousa MM, Vital C, Ostler D, Fernandes R, Pouget-Abadie J, Carles D, Saraiva MJ: Apolipoprotein Al and transthyretin as components of amyloid fibrils in a kindred with apoAl Leu178His amyloidosis. Am J Pathol 2000, 156:1911-1917

22. Gregorini G, Izzi C, Obici L, Tardanico R, Röcken C, Viola BF, Capistrano M, Donadei S, Biasi L, Scalvini T, Merlini G, Scolari F: Renal apolipoprotein A-I amyloidosis: a rare and usually ignored cause of hereditary tubulointerstitial nephritis. J Am Soc Nephrol 2005, 16:3680-3686

23. Bohne S, Sletten K, Menard R, Bühling F, Vöckler S, Wrenger E, Roessner $A$, Röcken $C$ : Cleavage of $A L$ amyloid proteins and $A L$ amyloid deposits by cathepsins B, K, and L. J Pathol 2004, 203:528-537

24. Kuci H, Ebert MP, Röcken C: Anti-lambda-light chain-peptide antibodies are suitable for the immunohistochemical classification of $\mathrm{AL}$ amyloid. Histol Histopathol 2007, 22:379-387

25. Hoshii Y, Setoguchi M, Iwata T, Ueda J, Cui D, Kawano H, Gondo T, Takahashi M, Ishihara T: Useful polyclonal antibodies against synthetic peptides corresponding to immunoglobulin light chain constant region for immunohistochemical detection of immunoglobulin light chain amyloidosis. Pathol Int 2001, 51:264-270

26. Ostertag. Familiäre Amyloid-Erkrankung. Z Mensch Vererb Konstitutions| 1950, 30:105-115

27. Andrade C: A peculiar form of peripheral neuropathy; familiar atypical generalized amyloidosis with special involvement of the peripheral nerves. Brain 1952, 75:408-427

28. Caballeria J, Bruguera M, Sole M, Campistol JM, Rodes J: Hepatic familial amyloidosis caused by a new mutation in the apolipoprotein Al gene: clinical and pathological features. Am J Gastroenterol 2001, 96:1872-1876

29. Eriksson M, Schönland S, Bergner R, Hegenbart U, Lohse P, Schmidt $H$, Röcken C: Three German fibrinogen Aalpha-chain amyloidosis patients with the p.Glu526Val mutation. Virchows Arch 2008, 453:25-31

30. Eriksson M, Büttner J, Todorov T, Yumlu S, Schönland S, Hegenbart U, Kristen AV, Dengler T, Lohse P, Helmke B, Schmidt H, Röcken C: Prevalence of germline mutations in the TTR gene in a consecutive series of surgical pathology specimens with ATTR amyloid. Am J Surg Pathol 2009, 33:58-65

31. Solomon A, Murphy CL, Kestler D, Coriu D, Weiss DT, Makovitzky J, Westermark P: Amyloid contained in the knee joint meniscus is formed from apolipoprotein A-I. Arthritis Rheum 2006, 54:3545-3550

32. Nichols WC, Dwulet FE, Liepnieks J, Benson MD: Variant apolipoprotein $\mathrm{Al}$ as a major constituent of a human hereditary amyloid. Biochem Biophys Res Commun 1988, 156:762-768

33. Röcken C, Menard R, Bühling F, Vöckler S, Raynes J, Stix B, Krüger $S$, Roessner A, Kähne T: Proteolysis of serum amyloid $A$ and $A A$ amyloid proteins by cysteine proteases: cathepsin $B$ generates AA amyloid proteins and cathepsin $L$ may prevent their formation. Ann Rheum Dis 2005, 64:808-815 